\title{
The onto-semiotic approach to research in mathematics education
}

\author{
Juan D. Godino · Carmen Batanero • \\ Vicenç Font
}

Accepted: 22 November 2006/Published online: 4 January 2007

(C) FIZ Karlsruhe 2007

\begin{abstract}
In this paper we synthesize the theoretical model about mathematical cognition and instruction that we have been developing in the past years, which provides conceptual and methodological tools to pose and deal with research problems in mathematics education. Following Steiner's Theory of Mathematics Education Programme, this theoretical framework is based on elements taken from diverse disciplines such as anthropology, semiotics and ecology. We also assume complementary elements from different theoretical models used in mathematics education to develop a unified approach to didactic phenomena that takes into account their epistemological, cognitive, socio cultural and instructional dimensions.
\end{abstract}

In memoriam of Hans-Georg Steiner who encouraged our interest in the Theory of Mathematics Education and helped us recognize its complexity, and the need for adopting a holistic, interdisciplinary and systemic approach in our research.

J. D. Godino $(\bowtie) \cdot$ C. Batanero

Departamento de Didáctica de la Matemática, Universidad de Granada, 18071 Granada, Spain

e-mail: jgodino@ugr.es

URL: http://www.ugr.es/local/jgodino

C. Batanero

e-mail: batanero@ugr.es

V. Font

Departament de Didàctica de les Ciències Experimentals i la Matemàtica, Universitat de Barcelona, 08035 Barcelona, Spain

e-mail: vfont@ub.edu

\section{The need for a comprehensive approach to mathematics education}

Mathematics Education is aimed to study the factors affecting the teaching and learning of mathematics and to develop programs to improve the teaching of mathematics. This goal was assumed by Steiner in his programme for the Theory of Mathematics Education, "the development of a comprehensive view of mathematics education comprising research, development, and practice by means of a systemic approach" (Steiner, 1985, p. 16).

In order to accomplish this aim Mathematics Education must consider the contributions of several disciplines: Psychology, Pedagogy, Sociology, Philosophy, etc. However, the use of these contributions in Mathematics Education should be based on an analysis of the nature of mathematics and mathematical concepts, and their personal and cultural development. Such epistemological analysis is essential in Mathematics Education, for it would be very difficult to suitably study the teaching and learning processes of undefined and vague objects.

Thus, research in Mathematics Education cannot ignore philosophical questions such as

- What is the nature of mathematical objects?

- What roles human activity and socio-cultural processes play in the development of mathematical ideas?

- Is mathematics discovered or invented?

- Do formal definitions and statements cover the full meaning of concepts and propositions?

- What role is played, in the meaning of mathematical objects, by their relationships with other 
objects, the problems in which they are used and the different symbolic representations?

The relatively recent emergence of Mathematics Education as a scientific discipline explains the lack of a consolidated and dominant research paradigm. Diverse survey works (Ernest, 1994; Font, 2002; Sierpinska, \& Lerman, 1996) oriented to provide proposals for organizing the different research programmes in Mathematics Education have shown the diversity of theoretical approaches that are being developed at present. This variety is unavoidable, even enriching at some moments, but the progress of the discipline and the strengthening of its practical applications require a collective effort to identify the firm nucleus of concepts and methods that, in the long run, should crystallize in a true research program, using Lakatos' (1983) terminology.

One main "meta-didactical" problem is the clarification of the theoretical notions that are used in the area of knowledge to analyse the cognitive phenomena, since we observe a variety of terms that have not been compared or clarified: knowledge, "savoir", competence, conception, concept, internal representation, conceptual image, invariant operative, meaning, etc.

Progress in the field requires contrasting these tools and possibly elaborating other new ideas that serve to more effectively carry out the intended work. It is also necessary to coherently articulate the diverse dimensions or facets implied, such as the ontological (types of objects and their nature), epistemological (access to knowledge), socio-cultural and instructional facets (teaching and learning in school institutions).

We believe it is necessary and possible to build a unified approach to mathematical knowledge and instruction that allows the overcoming of the dilemmas among the diverse competing paradigms: realismpragmatism, individualism-institutional knowledge, constructivism-behaviourism, etc. To progress in this direction we should take into account some conceptual and methodological tools from holistic disciplines such as Semiotics, Anthropology and Ecology, coherently articulated with other disciplines such as Psychology and Pedagogy, which traditionally are immediate reference for Mathematics Education.

The Onto-Semiotic Approach to Mathematics Education that we present in this paper is a "homegrown model" that assumes a systemic and interdisciplinary perspective (Steiner, 1985) to deal with the complexity of Mathematics Education as a field of research, development and practice.

\section{Towards a unified approach to mathematical knowledge and instruction}

For the past 12 years we have been interested in the foundations for Mathematics Education Research (Batanero, Godino, Steiner, \& Wenzelburger, 1994), and we have developed diverse theoretical tools to deal with some of the mentioned questions. These tools were based on several theoretical antecedents, which are described and analysed in Godino (2003, Chap. 2). ${ }^{1}$ These tools have been developed in three stages, in each of which the object of inquiry was progressively refined. Next, we succinctly describe these three stages and the issues dealt with in each of them.

During the period 1993-1998 (Godino, 1996; Godino, \& Batanero, 1994, 1998), we progressively developed and refined the notions of "institutional and personal meaning ${ }^{2}$ of a mathematical object" and their relationship to the notion of understanding. Starting from pragmatic assumptions, these ideas try to focus the interest of research on the institutional mathematical knowledge, without dismissing the individual subject towards which the educational effort is mainly addressed.

In a second stage (starting in 1998) we considered it necessary to elaborate a more specific ontological and semiotic model, since we realized that the epistemic and cognitive problems could not be separated from the ontological reflection. For this reason we were interested in elaborating an ontology sufficiently rich to describe mathematical activity and the processes of communicating their "products." We tried to progress in developing a specific ontology and semiotic to study the processes of interpreting the systems of mathematical signs used in didactic interactions.

These questions are central in other disciplines (such as Semiotics, Epistemology and Psychology), although they have not provided a clear solution to these issues. The available answers are diverse, incompatible or difficult to articulate, as we can see, for example, in the dilemmas outlined by the approaches of Peirce (1965), Saussure (1915) and Wittgenstein (1953). Moreover, the interest in using semiotic notions is also growing in mathematics education as it is shown in the monograph published by Anderson, Sáenz-Ludlow, Zellweger, and Cifarelli (2003) and the special issue of Educational Studies in Mathematics (Sáenz-Ludlow, \& Presmeg, 2006).

\footnotetext{
1 The publications of Godino et al. can be downloaded from Internet: http://www.ugr.es/local/jgodino.

${ }^{2}$ Here, meaning is interpreted in terms of systems of practices related to the object.
} 
We tried to provide a particular answer from the point of view of mathematics education, enlarging the investigations carried out so far on the institutional and personal meanings, and also adopting the idea of semiotic function and improving the associate mathematical ontology introduced in Godino and Recio (1998).

In a third stage of our work we have been interested in theoretical models for mathematical instruction (Godino, Contreras, \& Font, 2006). We defined six dimensions in a mathematical instruction process, each of them modelled as a stochastic process with its respective state space and trajectory: epistemic (relating to institutional knowledge), educational (teachers' roles), student (students' roles), mediational (use of technological resources and time), cognitive (genesis of personal meanings) and emotional (students' attitudes, emotions, etc. when studying mathematics) trajectories.

The theoretical constructs elaborated during these three periods constitute the onto-semiotic approach that we synthesize in the next section.

\section{Basic theoretical tools}

The starting point for the onto-semiotic approach was an ontology of mathematical objects that takes into account the triple aspect of mathematics as a socially shared problem-solving activity, a symbolic language and a logically organized conceptual system. Taking the problem-situation as the primitive notion, we defined the theoretical concepts of practice, (personal and institutional) object and meaning, with the purpose of making visible and operative, both the mentioned triple character of mathematics and the personal and institutional genesis of mathematical knowledge, as well as their mutual interdependence.

\subsection{Systems of operative and discursive practices linked to types of problems}

We consider mathematical practice any action or manifestation (linguistic or otherwise) carried out by somebody to solve mathematical problems, to communicate the solution to other people, so as to validate and generalize that solution to other contexts and problems (Godino, \& Batanero, 1998, p. 182). The practices can be idiosyncratic of a person or shared within an institution. An institution is constituted by the people involved in the same class of problem-situations, whose solution implies the carrying out of certain shared social practices and the common use of particular instruments and tools.
In the study of mathematics, more than a specific practice to solve a particular problem, we are interested in the systems of (operative and discursive) practices carried out by the people involved in certain types of problem-situations. For example, regarding the questions, What is the mathematical object ${ }^{3}$ "arithmetic mean"?, What does it mean or does it represent the expression "arithmetic mean"?, we propose the following pragmatist answer: "The system of practices that a person carries out (personal meaning), or are shared within an institution (institutional meaning), to solve a type of problem-situations in which finding a representative of a set of data is required."

The socio-epistemic and cognitive relativity of meanings, when they are understood as systems of practices, and their use in the didactical analysis lead to introducing a basic typology of meanings. Regarding institutional meanings we distinguish the following types:

- Implemented: the system of practices that a teacher effectively implements in a specific teaching experience.

- Assessed: the system of practices that a teacher uses to assess his/her students' learning.

- Intended: the system of practices included in the planning of the study process.

- Referential: the system of practices used as reference to elaborate the intended meaning, for example, that included in curricular documents. In a particular teaching experience the reference meaning will be part of a more global or holistic meaning, whose determination requires carrying out a historical and epistemological study to find the origin and evolution of the object.

Regarding the personal meaning we introduce the following types:

- Global: set of personal practices that the subject is potentially able to carry out related to a specific mathematical object.

- Declared: the personal practices effectively shown in solving assessment tasks and questionnaires independently, if they are correct or incorrect from the institutional point of view.

- Achieved: personal practices that fit the institutional meaning fixed by the teacher. The analysis of

\footnotetext{
${ }^{3}$ Initially we use the expression "mathematical object" as synonymous of "mathematical concept". Later we extend the use indicating any entity or thing to which we refer, or talk about it, be it real or imaginary and that intervenes in some way in mathematical activity.
} 
changes and evolution of personal meanings, as a result of the study process, will also serve to distinguish between initial and final personal achieved meanings.

In the onto-semiotic framework, teaching involves the participation of students in the community of practices sharing the institutional meaning, and learning is conceived as the students' appropriation of these meanings.

\subsection{Objects involved and emerging from systems of practices}

In mathematical practices ostensive (symbols, graphs, etc.) and non-ostensive objects (brought to mind when doing mathematics), which are textually, orally, graphically or even gesturally represented intervene. New objects that come from the system of practices and explain their organization and structure (types of problems, procedures, definitions, properties, arguments), emerge. ${ }^{4}$ If the system of practices is shared within an institution, the emerging objects are considered to be "institutional objects", whilst if these systems correspond to a person they are considered as "personal objects". 5 The following types of primary mathematical objects are proposed:

- Language (terms, expressions, notations, graphics);

- Situations (problems, extra- or intra-mathematical applications, exercises, etc.);

- Concepts, given by their definitions or descriptions (number, point, straight line, mean, function, etc.);

- Propositions, properties or attributes,

- Procedures (operations, algorithms, techniques);

- Arguments used to validate and explain the propositions and procedures (deductive, inductive, etc.).

These objects are organized in more complex entities, such as conceptual systems, theories, etc. The six types of primary objects postulated widen the traditional distinction between conceptual and procedural entities that is insufficient to describe the objects intervening and emerging from mathematical activity. The problem-situations promote and contextualize the activity; language (symbols, notations, graphics, ...) represent the other entities and serve as tools for action; arguments justify the procedures and propositions that relate the concepts. These entities have to be considered as functional and relative to the language

\footnotetext{
4 "... mathematical discourse and its objects are mutually constitutive" (Sfard, 2000, p. 47.)

5 "Personal objects" include cognitive constructs such as conceptions, internal representations, conceptual images, etc.
}

game (institutional frameworks and contexts of use) in which they participate; they have also a recursive character, in the sense that each object might be composed of other entities, depending on the analysis level, for example arguments might involve concepts, properties, operations, etc.

\subsection{Relations between objects: semiotic functions}

Another component in the model is Hjelmslev's (1943) notion of function of sign, ${ }^{6}$ that is the dependence between a text and its components and between these components themselves, in others words, the correspondences (relations of dependence or function) between an antecedent (expression, signifier) and a consequent (content, signified or meaning), established by a subject (person or institution) according to certain criteria or a corresponding code. These codes in mathematical activity can be rules (habits, agreements) that inform the subjects implied about the terms that should be put in correspondence in the fixed circumstances.

For us, the relations of dependence between expression and content can be representational (one object which is put in place of another for a certain purpose), instrumental (an object uses another as an instrument) and structural (two or more objects make up a system from which new objects emerge). In this way, semiotic functions and the associated mathematical ontology, take into account the essentially relational nature of mathematics and radically generalize the notion of representation. The role of representation is not exclusively undertaken by language: in accordance with Peirce's semiotic, we assume the different types of objects (problem-situations, procedures, definitions, propositions and arguments) can also be expression or content of the semiotic functions.

\subsection{Configuration of objects and mathematical processes}

The notion of "system of practices" is useful for some types of macro-didactic analysis, particularly when comparing the particular form mathematical knowledge adopts in different institutional frameworks, contexts of use or language games. A finer description of mathematical activity requires the introduction of the six types of primary entities. These objects will form "configurations", that we define as the network of objects involved and emerging from the systems of practices and the relationships established between

\footnotetext{
${ }^{6}$ Named by Eco (1979) as semiotic function.
} 
them. These configurations can be epistemic (networks of institutional objects) or cognitive (network of personal objects), and with the system of practices are the basic theoretical tools to describe mathematical knowledge, in its double personal and institutional facets.

These objects and relationships (configurations), emerge through time in both their personal and institutional facet, by means of mathematical processes, which we interpret as sequences of practices. The emergence of linguistic objects, problems, definitions, propositions, procedures and arguments take place throughout the respective primary mathematical processes of communication, problem posing, definition, enunciation, elaboration of procedures (algorithms, routines, ...) and argumentation. Problem solving and mathematical modelling should rather be considered as mathematical "hyper-processes", when involving complex configurations of primary mathematical processes (establishing connections between objects and generalizing techniques, rules and justifications). The effective realization of study processes also requires sequences of planning, monitoring and assessing that might be considered as meta-cognitive processes.

\subsection{Contextual attributes}

The notion of language game (Wittgenstein, 1953) plays an important role together with that of institution in our model. Here, we refer to contextual factors to which the meanings of mathematical objects are relative and which attribute a functional nature to them. Mathematical objects intervening in mathematical practices or emerging from them, depend on the language game in which they take part, and can be considered from the following dual dimensions or facets (Godino, 2002).

Personal-institutional Institutional objects emerge from systems of practices shared within an institution, while personal objects emerge from specific practices from a person (Godino and Batanero, 1998, pp. 185186). "Personal cognition" is the result of individual thinking and activity when solving a given class of problems, while "institutional cognition" is the result of dialogue, agreement and regulation within the group of subjects belonging to a community of practices.

Ostensive-non-ostensive Mathematical objects (both at personal or institutional levels) are, in general, non-perceptible. However, they are used in public practices through their associated ostensives (notations, symbols, graphs, etc.). The distinction between ostensive and non-ostensive is relative to the language game in which they take part. Ostensive objects can also be thought, imagined by a subject or be implicit in the mathematical discourse (for example, the multiplication sign in algebraic notation).

Extensive-intensive (example-type) An extensive object is used as a particular case (a specific example, i.e., the function $y=2 x+1$ ), of a more general class (i.e., the family of functions $y=m x+n$ ), which is an intensive object. The extensive/intensive duality is used to explain a basic feature of mathematical activity: the use of generic elements (Contreras, Font, Luque, \& Ordóñez, 2005). This duality allows us to focus our attention on the dialectic between the particular and the general, which is a key issue in the construction and application of mathematical knowledge.

Unitary-systemic In some circumstances mathematical objects are used as unitary entities (they are supposed to be previously known), while in other circumstances they are seen as systems that could be decomposed to be studied. For example, in teaching, addition and subtraction, algorithms, the decimal number system (tens, hundreds, ...) is considered as something known, or as unitary entities. These same objects, in first grade, should be dealt with as systemic and complex objects to be learned.

Expression-content They are the antecedent and consequent of semiotic functions. Mathematical activity is essentially relational, since the different objects described are not isolated, but they are related in mathematical language and activity by means of semiotic functions. Each type of objec7t can play the role of antecedent or consequent (signifier or signified) in the semiotic functions established by a subject (person or institution).

These facets are grouped in pairs that are dually and dialectically complementary. They are considered as attributes applicable to the different primary and secondary objects, giving rise to different "versions" of the said objects. In Godino, Batanero, and Roa (2005) the six types of primary entities and the five types of cognitive dualities are described using examples from a research in the field of combinatory reasoning.

In Fig. 1, we represent the different theoretical notions that have been concisely described as an ontosemiotic model for mathematical knowledge. Here, mathematical activity plays a central role and is modelled in term of systems of operative and discursive practices. From these practices the different types of mathematical objects, which are related among them building cognitive or epistemic configurations, emerge. Lastly, the objects that take part in mathematical practices and those emerging from these practices depend on the language game in which they participate, 


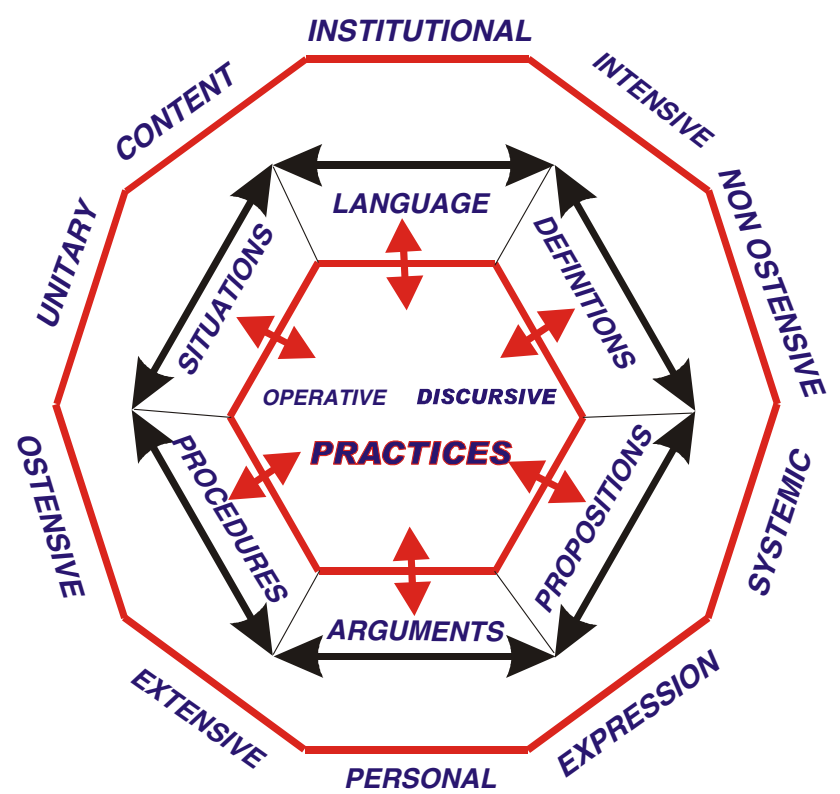

Fig. 1 An onto-semiotics of mathematical knowledge

and might be considered from the five facets of dual dimensions.

The types of objects described, summarized in Fig. 1 (systems of practices, emerging entities, configurations or onto-semiotic networks, the contextual attributes, together with the notion of semiotic function as the basic relational entity) make up an operative response to the ontological problem of representation and meaning of mathematical knowledge.

\subsection{Understanding and knowing \\ in the onto-semiotic approach}

There are two basic ways to conceive "understanding": as a mental process or as a competence (Font 2001), which correspond to divergent or even conflicting epistemological conceptions. Cognitive approaches in Mathematics Education view understanding as a mental process, while the pragmatic position of the onto-semiotic approach considers understanding as competence (a subject is said to understand a mathematical object when he/she uses it in a competent way in different practices).

However, considering the essential role played by the semiotic functions in the relational process carried out in mathematical activity (within a given language game) also lead to conceiving understanding in terms of semiotic functions (Godino, 2003). That is, we can interpret understanding of an object $O$ by a subject $\mathrm{X}$ (person or institution) in terms of the semiotic functions that $\mathrm{X}$ can establish, in some fixed circumstances, in which $O$ intervenes as expression or content. Each semiotic function implies a semiosis act by an interpretant agent and constitutes a knowledge. Speaking of knowledge is equivalent to speaking of the content of a (or many) semiotic function (s), and the variety of types of knowledge correspond to the diversity of semiotic functions that can be established among the diverse entities introduced in the theoretical model.

\subsection{Didactical problems, practices, processes and objects}

The theoretical model described for mathematical education can also be applied to other fields, particularly to pedagogical knowledge. In this case the problems from which knowledge emerge have a different nature, e.g.,

- What content should be taught in each context and circumstances?

- How should we allocate the diverse components and facets of contents through time?

- What model of the study process should be implemented in each circumstance?

- How should we plan, monitor and assess the teaching and learning processes?

- What factors condition the teaching and learning processes?

Here, the actions (didactical practices) implemented, their sequencing (didactical processes) and the emergent objects from these systems of practices (didactical objects) will be different from those arising in solving mathematical problems.

In the Theory of Didactical Configurations (Godino et al., 2006) that we are developing as a component of the onto-semiotic approach, we model the teaching and learning of a mathematical content as a multidimensional stochastic process composed of six sub-processes (epistemic, teacher's roles, students' roles, mediational, cognitive and emotional), and their respective trajectories and potential states. We introduce the didactical configuration as the primary unit for didactical analysis. This is constituted by the teacher-student interactions when studying a mathematical object or content and using some specific technological resources. Every instructional process is developed for a given time through a sequence of didactical configurations.

A didactical configuration includes an epistemic configuration, that is to say, a mathematical problem, the languages and actions required to solve it, rules (concepts, propositions and procedures), and argumentations, which are assumed by the teacher, students, or shared between them. There is also an 
instructional configuration made up by the teacher, students and the mediational objects (different resources) related to the mathematical content under study. The learning built throughout the process might be viewed as a set of cognitive configurations, that is the networks of objects emerging from or involved in the systems of personal practices that students carried out during the implementation of the epistemic configuration.

\subsection{Didactical suitability criteria}

We complement the theoretical notions described with the notion of didactical suitability of an instructional process, which is defined as the coherent and systemic articulation of the following six components (Godino, Wilhelmi, \& Bencomo, 2005; Godino et al., 2006), each of which is a matter of degree:

- Epistemic suitability: representativeness of institutional implemented (or intended) meaning as regards the reference meaning previously defined.

- Cognitive suitability: extent to which the institutional implemented (or intended) meaning is included in the students' "zone of proximal development" (Vygotski, 1934), and the closeness of personal meanings achieved to implemented (or intended) meaning.

- Interactive suitability: extent to which the didactical configurations and trajectories allow to identify and solve semiotic conflicts ${ }^{7}$ that might happen during the instructional process.

- Media/resources suitability: availability and adequacy of material and temporal resources needed to develop the teaching and learning process.

- Emotional suitability: the students' involvement (interest, motivation, ...) in the study process.

- Ecological suitability: extent to which the teaching and learning process fits the educational project, the school and society, and take into account the conditioning factors of the setting in which it is developed.

A higher suitability in one of these dimensions might not correspond to a high level of suitability in the other dimensions. Given preference to the different criteria will depend on the interactions among them; we then introduce didactical suitability as a systemic criteria of adequacy and appropriateness regarding the global educational project. This didactical suitability is rela-

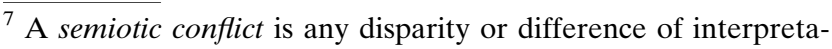
tion between the meanings ascribed to an expression by two subjects (persons or institutions).
}

tive to temporal, contextual and changing circumstances, which requires an inquiring and reflective attitude from the teacher and the people sharing the responsibility of an educational project.

The theoretical tools developed in the onto-semiotic approach to mathematical knowledge and instruction can be applied to analyse the teaching and learning process implemented in a particular teaching session, the planning and development of a didactical unit, or at a more global level, in the design and implementation of a course or curricular proposal. They also can be useful to analyse partial aspects of a study process, such as the didactical resources, textbooks, students' answers to specific tasks, etc.

\section{Examples of application and comparison with other frameworks}

Due to the space limitation it is not possible to describe a complete example of application of the framework described, which is being used as the theoretical background for several dissertations, articles and research reports. Some of these examples are described in the authors' web sites. To follow, we have prepared a short abstract of the application of the onto-semiotic approach in the research of Godino et al. (2005), where they describe the mathematics activity carried out by a sample of university students when solving elementary combinatoric problems.

Our theoretical tools served to identify the variety of mathematical objects involved in combinatorial problem solving, beyond classical combinatorial formulae and showed examples for the cognitive dualities from which they can be considered, so as the semiotic functions that can be established among them. The students' errors and difficulties were explained by semiotic conflicts, i.e., as disparities between the student's interpretation and the meaning in the mathematics institution. As a result of this application, we provided original and relevant information to better understand the students' combinatorial thinking. The analysis also showed some "transparency illusions" in the teaching and assessing of combinatorics and suggested some ways to improve this teaching.

We believe the onto-semiotic approach might help compare the theoretical frameworks used in Mathematics Education and, to the same extent, to overcome some of their limitations for the analysis of mathematics cognition and instruction. The key role that we give to the notion of mathematical practice, and the features we attribute to it (any shared, situated, intentional action mediated by linguistic and material 
resources) might allow a coherent articulation with other theoretical frameworks, such as the social constructivism (Ernest, 1998), the socio-epistemology (Cantoral, \& Farfán, 2003), and the ethno-mathematical and socio-cultural approach to mathematical meaning and cognition (Radford, 2006).

In Godino, Font, Contreras and Wilhelmi (2006) we use the onto-semiotic approach to analyse and compare other theoretical frameworks, in particular, the theory of didactical situation (Brousseau, 1997), conceptual fields (Vergnaud, 1990), dialectic tool-object (Douady, 1986), anthropological theory of didactics (Chevallard, 1992), and semiotic registers (Duval, 1995).

\section{Final reflections}

The onto-semiotic approach is growing as a theoretical framework for Mathematics Education impelled by issues related to teaching and learning mathematics and the aspiration of achieving the articulation of the diverse dimensions and perspectives involved. In agreement with Steiner (1990), we are convinced that this work of articulation cannot be made through the superimposition of tools taken from different and heterogeneous theories. He conceived Mathematics Education as a scientific discipline in the centre of a complex, heterogeneous, social system-the System of Teaching Mathematics-and proposed beside Mathematics other referential sciences for our discipline, such as: Epistemology, Psychology Pedagogy Sociology and Linguistics. Each of these disciplines focuses its attention on partial aspects of the issues involved in teaching and learning mathematics, using their specific conceptual tools and methodologies. At a certain time, this diversity of approaches might be inevitable, or even enriching, but we think that the progress in the discipline and the strengthening of its practical applications requires the emergence of a new global and unifying perspective.

Acknowledgment This research work has been carried out in the frame of the project, MCYT- FEDER: SEJ2004-00789.

\section{References}

Anderson, M., Sáenz-Ludlow, A., Zellweger, S., \& Cifarelli, V. C. (Eds). (2003). Educational perspectives on mathematics as semiosis: From thinking to interpreting to knowing. Otawa: Legas.

Batanero, C., Godino J.D., Steiner, H.G., \& Wenzelburger, E. (1994). The training of researchers in Mathematics Education. Results from an International study. Educational Studies in Mathematics, 26, 95-102.
Brousseau G. (1997). Theory of didactical situation in mathematics. Dordrecht: Kluwer.

Cantoral, R., \& Farfán, R. M. (2003). Matemática educativa: Una visión de su evolución. Revista Latinoamerica de Investigación en Matemática Educativa, 6(1), 27-40.

Chevallard, Y. (1992). Concepts fondamentaux de la didactique: perspectives apportées par une approche anthropologique. Recherches en Didactique des Mathématiques, 12(1), 73-112.

Contreras, A., Font, V., Luque, L., \& Ordóñez, L. (2005). Algunas aplicaciones de la teoría de las funciones semióticas a la didáctica del análisis infinitesimal. Recherches en Didactique des Mathématiques, 25(2), 151-186.

Douady, R. (1986). Jeux de cadres et dialectique outil-objet. Recherches en Didactique des Mathématiques, 7(2), 5-31.

Duval R. (1995). Sémiosis et penseé humaine. Berna: Peter Lang.

Eco, U. (1979). Tratado de semiótica general. Barcelona: Lumen, 1991.

Ernest, P. (1994). Varieties of constructivism: their metaphors, epistemologies and pedagogical implications. Hiroshima Journal of Mathematics Education, 2, 1-14.

Ernest, P. (1998). Social constructivism as a philosophy of mathematics. New York: SUNY.

Font, V. (2001). Processos mentals versus competència, Biaix 19, pp. 33-36.

Font, V. (2002). Una organización de los programas de investigación en Didáctica de las Matemáticas. Revista EMA, 7(2), 127-170.

Godino, J. D. (1996). Mathematical concepts, their meanings, and understanding. In L. Puig, \& A. Gutierrez (Eds.), Proceedings of the 20th Conference of the International Group for the Psychology of Mathematics Education (pp. 2417-424), University of Valencia.

Godino, J. D. (2002). Un enfoque ontológico y semiótico de la cognición matemática. Recherches en Didactiques des Mathematiques, 22(2/3), 237-284.

Godino, J. D. (2003). Teoría de las funciones semióticas. Un enfoque ontológico-semiótico de la cognición e instrucción matemática. Departamento de Didáctica de la Matemática. Universidad de Granada. (Available at http://www.ugr.es/ local/jgodino/indice_tfs.htm).

Godino, J. D., \& Batanero, C. (1994). Significado institucional y personal de los objetos matemáticos. Recherches en Didactique des Mathématiques, 14(3), 325-355.

Godino, J. D., \& Batanero, C. (1998). Clarifying the meaning of mathematical objects as a priority area of research in mathematics education. In A. Sierpinska \& J. Kilpatrick (Eds.), Mathematics Education as a Research Domain: A Search for Identity (pp. 177-195). Dordrecht: Kluwer

Godino, J. D., \& Recio, A. M. (1998). A semiotic model for analysing the relationships between thoughy, language and context in mathematics education. In A. Olivier \& K. Newstead (Eds.), Proceedings of the 22nd Conference of the International Group for the Psychology of Mathematics Education, vol. 3 1.8. University of Stellenbosch, South Africa.

Godino, J. D., Batanero, C., \& Roa, R. (2005). An onto-semiotic analysis of combinatorial problems and the solving processes by university students. Educational Studies in Mathematics, 60(1), 3-36.

Godino, J. D., Wilhelmi, M. R., \& Bencomo, D. (2005). Suitability criteria of a mathematical instruction process. A teaching experience of the function notion. Mediterranean Journal for Research in Mathematics Education, 4.2, 1-26.

Godino, J. D., Contreras, A., \& Font, V. (2006). Análisis de procesos de instrucción basado en el enfoque ontológico- 
semiótico de la cognición matemática. Recherches en Didactiques des Mathematiques, 26(1), 39-88.

Godino, J. D., Font, V., Contreras, A., \& Wilhelmi, M. R. (2006). Una visión de la didáctica francesa desde el enfoque ontosemiótico de la cognición e instrucción matemática. Revista Latinoamerica de Investigación en Matemática Educativa, 9(1), 117-150.

Hjelmslev, L. (1943). Prolegómenos a una teoría del lenguaje. Madrid: Gredos, 1971.

Lakatos, I. (1983). La metodología de los programas de investigación científica. Madrid: Alianza.

Peirce, Ch. S. (1965). Obra lógico-semiótica. Madrid: Taurus, 1987

Radford, L. (2006). The anthropology of meaning. Educational Studies in Mathematicas, 61(1-2), 39-65.

Sáenz-Ludlow, A., \& Presmeg, N. (2006). Semiotic perspectives on learning mathematics and communicating mathematically. Educational Studies in Mathematics, 61(1-2), 1-10.

Saussure, F. (1915). Curso de lingüística general. Madrid: Alianza, 1991.

Sfard, A. (2000). Symbolizing mathematical reality into being-Or how mathematical discourse and mathematical objects create each other. In P. Cobb, E. Yackel, \& K. McCain (Eds.), Symbolizing and Communicating in Mathematics Classroom (pp. 37-97). London: LEA.

Sierpinska, A., \& Lerman, S. (1996). Epistemologies of mathematics and of mathematics education. In A. J. Bishop, et al. (Eds.), International Handbook of Mathematics Education (pp. 827-876). Dordrecht: Kluwer

Steiner, H. G. (1985). Theory of mathematics education (TME): an introduction. For the Learning of Mathematics, 5(2), 1117.

Steiner, H. G. (1990). Needed cooperation between science education and mathematics education. Zentralblatt für Didaktik der Mathematik, 6, 194-197.

Vergnaud, G. (1990). La théorie des champs conceptuels. Recherches en Didactiques des Mathématiques, 10(2,3), 133-170.

Vygotski, L. S. (1934). El desarrollo de los procesos psicológicos superiores, $2^{\text {a }}$ edición. Barcelona: Crítica-Grijalbo, 1989.

Wittgenstein, L. (1953). Investigaciones filosóficas. Barcelona: Crítica. 